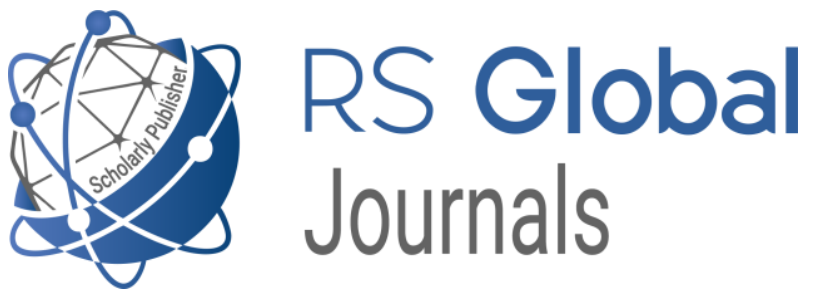

Scholarly Publisher

RS Global Sp. z O.O.

ISNI: 0000000484952390

Dolna 17, Warsaw, Poland 00-773

Tel: +48226022703

Email: editorial_office@rsglobal.pl

JOURNAL International Journal of Innovative Technologies in Social Science

p-ISSN $2544-9338$

e-ISSN

2544-9435

PUBLISHER

RS Global Sp. z O.O., Poland

ПРИЛАГАТЕЛЬНОЕ КАК СПОСОБ

ARTICLE TITLE ДЕПЕРСОНАЛИЗАЦИИ СООБЩЕНИЯ: АКТАНТНОПЕРЕМЕННАЯ ФУНКЦИЯ ПАССИВА (КЛАССИЧЕСКИЙ ПОДХОД)

$\operatorname{AUTHOR}(\mathbf{S})$

Н. В. Соловей, С. Д. Исаева

N. V. Solovey, S. D. Isaieva. (2021) Adjective as a Method of Depersonalization of Message: Actant-Alternating Function of

ARTICLE INFO Passive (Classical Approach). International Journal of Innovative Technologies in Social Science. 2(30). doi: 10.31435/rsglobal_ijitss/30062021/7553

DOI https://doi.org/10.31435/rsglobal_ijitss/30062021/7553

RECEIVED

10 April 2021

ACCEPTED

20 May 2021

PUBLISHED

25 May 2021

LICENSE

This work is licensed under a Creative Commons Attribution 4.0 International License.

(C) The author(s) 2021. This publication is an open access article. 


\title{
ПРИЛАГАТЕЛЬНОЕ КАК СПОСОБ ДЕПЕРСОНАЛИЗАЦИИ СООБЩЕНИЯ: АКТАНТНО- ПЕРЕМЕННАЯ ФУНКЦИЯ ПАССИВА (КЛАССИЧЕСКИЙ ПОДХОД)
}

\begin{abstract}
Н. В. Соловей, кандидат филологических наук, дочент, зав. кафедры иностранных языков математических факультетов, Киевский национальный университет имени Tараса Шевченко, г. Киев, Украина, ORCID ID: https://orcid.org/0000-0003-3100-8630

С. Д. Исаева, кандидат педагогических наук, доцент, доиент кафедры иностранных языков математических факультетов, Киевский национальный университет имени Tараса Шевченко, г. Киев, Украина, ORCID ID: https://orcid.org/0000-0003-4641-0534
\end{abstract}

DOI: https://doi.org/10.31435/rsglobal_ijitss/30062021/7553

\section{ARTICLE INFO}

Received 10 April 2021

Accepted 20 May 2021

Published 25 May 2021

\section{KEYWORDS}

perspective, predication, subject, adjective, derivative, structural.

\begin{abstract}
Semantic perspective of the sentences with passive predication, expressed by the verb in passive voice or using verbal adjectives with passive meaning is analysed in the article. Such types of predication are considered as categorial and noncategorial means of Passive Perspective expression respectively (grammatical and non-grammatical). The general characteristics of the sentences presented by the categorial passive or by non-categorial means are: absence of Agence in grammatical subject position, centripetal direction of the process, expressed by the predicate words and affection of grammatical subject. All these testify the identical character of the expressed relations (by them). Perspective (the direction of the action in the sentence) is defined by subject-object and has the identical nature in both variants.
\end{abstract}

Citation: N. V. Solovey, S. D. Isaieva. (2021) Adjective as a Method of Depersonalization of Message: Actant-Alternating Function of Passive (Classical Approach). International Journal of Innovative Technologies in Social Science. 2(30). doi: 10.31435/rsglobal_ijitss/30062021/7553

Copyright: (C) 2021 N. V. Solovey, S. D. Isaieva. This is an open-access article distributed under the terms of the Creative Commons Attribution License (CC BY). The use, distribution or reproduction in other forums is permitted, provided the original author(s) or licensor are credited and that the original publication in this journal is cited, in accordance with accepted academic practice. No use, distribution or reproduction is permitted which does not comply with these terms.

Введение. Актуальной проблемой лингвистики на протяжении многих лет остается изучение предложения с позиций семантического синтаксиса. Актуальным в этой связи остается изучение вариативного представления различных внеязыковых ситуаций языковыми средствами, включая различный ракурс их представления, отражающей особенности осмысления описываемой ситуации прагматическим субъектом. Проблема специфики языковой интерпретации описываемой в предложении ситуации продолжает оставаться актуальной $[1 ; 2]$ и говорит о неослабевающем интересе исследователей к особенностям семантико-синтаксической организации предложения.

Цель статьи - продемонстрировать классические способы выражения пассивной перспективы английского предложения как ее грамматикализованного варианта, так и неграмматические способы (посредством отглагольного имени прилагательного).

Материалы и методы. Материалом для статьи послужили предложения с пассивной перспективой главной и вторичной предикации, отобранные из художественных и научных текстов современных английских и американских авторов, лексикографических источников. Основными лингвистическими методами анализа в данной статье являются дефиниционный, валентностный, трансформационный. Основой статьи является положение о взаимосвязи языка 
и мышления, свойственном им взаимодействии в речемыслительных процессах соответственно потребностям коммуникации. Классический подход в изучении того или иного явления в языке необходим для дальнейших исследований, а также применения инновационных методов и моделей анализа языка, современных тенденций в изучении лингвистики.

Результаты исследования и обсуждения результатов. Пассивная перспектива свойственна предложениям, именная часть составного сказуемого которых выражена отглагольным прилагательным, имеющим подобно глаголу значение признака и характеризующегося подобно глаголу предикатным характером семантики.

С логической точки зрения предложения, в роли грамматических предикатов которых выступают переходные глаголы в пассивном залоге, либо отглагольные прилагательные, являются высказываниями об объектно-субъектных отношениях и относятся к разряду реляционных с логической формулой хРу. Другими словами, такие предложения отражают отношение между аффицированным объектом и агенсом и отличаются друг от друга структурными схемами как соответственно глагольные и адъективные.

Прилагательные, связанные словообразовательными отношениями с переходными глаголами, выявляют способность передавать пассивную перспективу главной предикации, употребляясь в предикативных позициях предложения. Данная способность рассматриваемых единиц объясняется возможностью наследовать пассивное значение исходной единицы деривации - переходного глагола [3]. Мотивирующая основа - переходной глагол, употребляющийся в пассивном залоге, является как минимум двухвалентным и содержит в своей лексической семантике реляционные семы (субъект) и (объект). Данное реляционное значение глагола отражается в семантике его производных - отглагольных прилагательных.

Наличие двух противоположных сем дает возможность двухвалентному глаголу описывать называемую им ситуацию со стороны субъекта, либо объекта и служить источником деривации активных и пассивных прилагательных.

Пассивные прилагательные и глаголы в пассивном залоге можно рассматривать как семантические корреляты, функциональное сближение которых обеспечивает их взаимозамену в тексте, основывающуюся на вариативности глагольных и адъективных номинаций [4, с.72].

Ср. параллельное использование переходного глагола и отглагольного прилагательного в предложениях: She begged him not to comfort her: She could not bear it (Forster). If the early argument had been painful to listen to the present one, concerning herself, was unbearable (Austen).

О пассивном характере данных прилагательных свидетельствуют, в частности, их словарные дефиниции, содержащие пассивную форму глагола, участвующего в толковании значения производного от него отглагольного прилагательного: permissible - that may be permitted (Hornby); allowable - that is or can be allowed (by law, the rules, etc.) (Hornby).

Наличие существования трансформационных связей между глаголом в пассивном залоге и прилагательным на -able установлено в результате лингвистического анализа, базирующегося на генеративно-трансформационном подходе в изучении языка [5]. Отглагольные прилагательные с пассивным значением образуются также при помощи и других суффиксов: -ful, -less, -ive, -some, -ory, -ary и т.д.

Варьирование семантической перспективы ядъективных предложений может обеспечиваться использованием в предикативных позициях отглагольных прилагательных, мотивированных пассивной и активной залоговыми формами - переходного глагола соответственно и имеющих вследствие этого различные залоговые значения. Cp.: permissible that may be permitted; permissive - giving permission, allowing discretion (Webster). A little contrivance to ensure that a visitor can sometimes find less than four at home is surely permissible (Austen)....direct primary legislation is largely permissive rather than prescriptive (Webster).

Пассивная перспектива главной предикации адъективных предложений передается посредством отглагольных прилагательных - синтаксических дериватов, характеризующихся идентичным управлением (синтаксической сочетаемостью, валентностью) с производящей основой. Как и глаголу в пассивном залоге, таким прилагательным свойственна обязательная субъектная и объектная семантическая валентность и обязательная объектная и факультативная субъектная синтаксическая валентность, которая может быть реализована, либо может оставаться нереализованной в предложении [4]: What you have done is only excusable in consideration of your youth... (Gaskell). A stretch of naked wrist was always visible between his cuffs 
and his red, bony, restless hands (Austen). ... a tragic whisper ... have been perfectly audible to everybody in the room (Wilde).

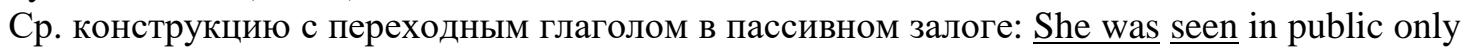
with Frederik (Spark) - She was seen (by X).

Невыраженность субъекта в синтаксической структуре предложения с пассивной перспективой, выраженной косвенно, может оказаться прагматически значимой. Так, субъект в пассивных конструкциях регистра научной прозы имеет обобщенно-личный характер, субъект, имплицируемый в конструкциях художественной прозы, часто имеет неопределенно-личный характер. Субъект может оставаться нереализованным, если он ясен из контекста. Например: For low and medium energy region the applicability of the model is questionable (Beljaev). A project ... which now appeared almost attainable occupied her thoughts (Austen). A subdued impassionel murmur was audible in the room beyond, and Miss Baker leaned forward unashamed, trying to her (Fitzgerald).

Субъект может быть неизвестен автору высказывания. Импликация субъекта действия может быть умышленной в случае нежелания автора высказывания приписать определенному лицу ответственность за какое-либо действие (проступок). Кроме того, субъект часто опускается во избежание построения громоздких конструкций, в которых субъект действия выражен с помощью сочетания by + N [6].

Предложениям с пассивной перспективой, содержащим пассивные прилагательные синтаксические дериваты - свойственно выражать неингерентное (непостоянное) свойство лица или предмета, обозначаемого подлежащим. Таким свойством (признаком) является протекающий во времени процесс: I thought you dandies never got up till two, and were not visible $\underline{\text { till five (Wilde). }}$

Лексическое значение прилагательных - центральных компонентов структур с пассивной предикацией - отличается большей конкретностью по сравнению с лексическим значением, например, существительных, что позволяет им вносить дополнительные семы (модальность, отрицание), отражающиеся в значении всей структуры:

1) Only the place in which we slept were free from intrusion (Green). 2) Bred is exempt from taxation (Longman). Cр. словарные дефиниции данных прилагательных: free (from) - without: exempt from) - 1) not liable to; 2) free(d) (from) (Longman).

Все вышесказанное говорит о семантической связи глагола в пассивном залоге и прилагательного - синтаксического деривата, что позволяет этим единицам, связанным отношениями семантической корреляции, взаимозаменяться в тексте. Такая корреляция основывается на вариативном характере глагольной и адъективной номинации, тождественные характеристики которого обеспечивают описание процесса в предложениях, Прагматический пик [7] которых представлен не-агенсом. Например: Can the existence of such enormously concentrated gravitational intensities be detected somehow at great distances? ... Gravitations ... cannot conceivably be detectable unless present in unusually high energies ... (Universals in Linguistics Theory).

Пассивная перспектива свойственна также главной предикации адъективных предложений, выражаемой отглагольными прилагательными, не являющимися синтаксическими или лексическими дериватами, а представляющими собой некий промежуточный тип производных единиц (ср. прилагательные с семой «пассив») [4, с. 73-83]. Для прилагательных данной группы свойственна обязательная семантическая субъектная и объектная валентности, однако, на уровне синтаксиса они реализуют лишь объектную валентность, что же касается субъектной валентности, то она у них не является активной, поскольку никогда не реализуется в предложении. Таким прилагательным свойствен ингерентный (постоянный) характер выражаемого ими признака, который препятствует реализации семантической субъектной валентности на синтаксическом уровне, наделяя имплицитный субъект обобщенным значением: The man was right and would have been lovable (Forster) - The man would have been loved (by anybody, everybody). The book is readable. Cp.: readable - that is easy or pleasant to read (Hornby).

В предложениях с отглагольными прилагательными-предикативами двух рассматриваемых типов кроме структурных различий имеются также различия семантического плана: они представляют собой поверхностные реализации различных семантических типов предложений. Первые, с активной синтаксической валентностью относятся к реляционным 
предложениям с логической формулой хРу, например: ... a tragic whisper ... have been perfectly audible to everybody in the room (Wilde).

Предложения второго типа, включающие прилагательные с потенциальной семантической субъектной валентностью, реализации которой препятствует ингерентный характер выражаемого ими признака, не являются чисто реляционными предложениями. В плане семантики такие предложения относятся к детерминирующим с логической формулой $\mathrm{P}(\mathrm{x})$. Поскольку предикативную позицию таких предложений занимают пассивные прилагательные, двухвалентные на семантическом уровне, правомерным представляется отнесение таких предложений к промежуточному типу реляционно-детерминирующих предложений [7, с.86]: He was very graceful and_lovable; but he found it difficult to learn (Lawrence). But when one sees the perfect Ibsen, how one hates the Norwegian and Swedish nations: They are detestable (Lawrence).

Пассивная перспектива характерна для предложений с прилагательнымипредикативами, образованными с помощью и других суффиксов. Нерасчлененность залогового значения, свойственная некоторым прилагательным, разрешается выбором ИГ (именной группы) на роль ПрП (прагматического пика): предложения с такими прилагательнымипредикативами, подлежащие которых характеризуются ролью не-агенса, свойственна пассивная перспектива и, напротив, предложения, подлежащие которых обозначают активных производителей действия (процесса, состояния), характеризуются активной перспективой. Ср.: -ful (doubtful - feeling doubt; causing doubt), -ous (suspicious - having, showing or causing suspicion). Например: 1) The result of the race is doubtful until it's over (пассивная перспектива) и I am doubtful that I'll be able to go to the party (5) (активная перспектива). 2) Then excuse is suspicious to me (пассивная перспектива) и I was suspicious of Ann (активная перспектива).

Варьирование семантической перспективы свойственно реляционным предложениям, валентностные особенности предикатов которых обусловливают возможность представления их пропозиционального содержания в разных ракурсах. Варьирующаяся семантическая перспектива свойственна предложениям, включающим симметричные и конверсивные предикаты, связанные отношениями обязательной, одновременной и взаимной импликации, равно как и глаголы-предикаты, допускающие залоговые преобразования [8].

Характерной особенностью реляционных и реляционно-детерминирующих предложений является то, что основная смысловая и коммуникативная нагрузка падает у них на отглагольное прилагательное. В роли подлежащих (Прагматических Пиков) таких предложений, как правило, выступает не-агенс.

Кроме прилагательных-синтаксических дериватов и прилагательных с промежуточным типом деривации, в корпус неграмматических способов выражения пассивной перспективы предложения входят также исконные (непроизводные) прилагательные, в семантических структурах которых обнаруживается сема пассива. $\mathrm{O}$ наличии пассивной семы свидетельствуют, в частности, словарные дефиниции таких прилагательных: popular - liked and admired (Hornby), familiar - well known to (Hornby). Yes, he did, and he won't be popular with the people here. I wonder whether he will be popular with us (Steinbeck). Amah was unpopular with the other man (Green). She is very popular, though she is no longer young (Lawrence). Facts that are familiar to every schoolboy. Subjects that are familiar to you (Webster).

Как видим, прилагательное popular и familiar, подобно отглагольным прилагательнымсинтаксическим дериватам, характеризуются активной семантической субъектной и объектной валентностью. На синтаксическом уровне объектная валентность является активной, а субъектная - факультативной, т.е. семантический субъект может выражаться в поверхностной структуре, либо оставаться имплицируемым. Предложения, в предикативных позициях которых находятся такие прилагательные, относятся к логико-семантическому разряду реляционных предложений с логической формулой хРу.

Пассивная перспектива главной предикации адъективных предложений задается семантической ролью не-агенса именной группы в позиции грамматического субъекта. Таким образом, понятие семантическая перспектива предложения задается 'свойством' его грамматического субъекта. Свойство подлежащего задавать характер перспективы позволяет рассматривать передачу предложением информации как выбранный прагматическим субъектом ракурс ее представления. Формирование стратегии передачи информации 
происходит на уровне языка, реализация же такой стратегии имеет место на уровне речи [9]. Кроме того, при создании речевого произведения, главное место отводится адресату. Адресату неизвестно, что ему сообщит собеседник, поэтому чтобы привлечь внимание, говорящий обозначает топик своего рассказа (свою тему, перспективу) [10, с.19].

Адъективные предложения-высказывания с пассивной перспективой, включающие прилагательные с пассивной семой, используются в контексте речевых актов констативов, а также речевых актов, выражающих разного рода оценки. Например:

Happily married people are invisible to the outside world (Ellis). At this point it was both inconceivable to her (Spark). For the rest, the only thing to eat - though it didn't look eatable... was a few lumps of some stuff like half-cooked dough (Conrad).

Несомненный интерес в корпусе таких высказываний представляют прилагательные определения имени существительного в предикативной позиции, являющиеся обязательными (моделеобразующими) членами предложения. Cp.: It would be an incalculable loss (Conrad) и It would be a loss.

Высказывания, выражающие исходящую от говорящего оценку явлений, фактов, Е.М. Вольф рассматривает как самостоятельный тип речевых актов [11].

Изучение перспективной организации английского предложения со свойственной ему спецификой помещения грамматического субъекта в позицию прагматического пика позволяет вскрыть синхронную многозначность имени (или его субститута) в позиции грамматического субъекта предложений с активной и пассивной перспективой, представляющую собой случай позиционного синкретизма.

Выводы. Варьирование семантической перспективы свойственно реляционным предложениям, валентностные особенности предикатов которых обусловливают возможность представления их пропозиционального содержания в разных ракурсах. Варьирующаяся семантическая перспектива свойственна предложениям, включающим симметричные и конверсивные предикаты, связанные отношениями обязательной, одновременной и взаимной импликации, равно как и глаголы-предикаты, допускающие залоговые преобразования.

\section{REFERENCES}

1. Bruce I. (2013). Theory and Concepts for Academic Purposes. Palgrave Macmillan. [in English]

2. Thompson D. (2012). Getting at the Passive: Functions of passive-types in English. PhD thesis. University of Glasgo. URL: http://eleanor.lib.gla.ac.uk/record =b2969171 [in English]

3. Solovey N., Mazur S., Letunovska I. (2020). Variatyvnist vyrazhennia dotsentrovoho napravlennia dii u rechenniakh. [Variability of expression of the centripetal direction of action in sentences]. Zaporizhzhia: Visnyk «Filolohichni nauky». [in Ukrainian]

4. Medvedeva L. (1983). Chasti rechi i zalog. [Parts of speech and voice]. Kiev: Vysshaya shkola. [in Russian]

5. Werner A. (1970). A Criterion of Naturalness in Grammatical Analysis: The Adjective. Papers in Linguistics, V.3., №1. [in English]

6. Perkins G. (1964). Writing Clear Prose. Chicago: Scott, Foresman and Company. [in English]

7. Mathesius V. (1975). A Functional Analysis of Present Day English on a General Linguistic Basis. The Hague-Paris: Monton. [in English]

8. Solovey N. (1988). Passivnaya perspektiva angliyskogo predlozheniya. [Passive perspective of the English sentence]. PhD thesis. Kiev: Kiev State University named after T.G.Shevchenko. [in Russian]

9. Rudsanger H. (1985). Sats, Structure och Perspective: Subjekt-diskussioner. Uppsala Univ. [in English]

10. Kubryakova E. (1986). Nominativnyy aspekt rechevoy deyatelnosti. [Nominative aspect of speech activity]. Moskva: Nauka. [in Russian]

11. Volf E. (1985). Funktsionalnaya semantika otsenki [Functional semantics of evaluation]. Moskva: Nauka. [in Russian] 